\title{
Famílias e eleições municipais em Londrina
}

\author{
Carla Andréia Alves da Silva Marcelino ${ }^{1}$
}

- Enviado em 15/09/2016

- Aprovado em 18/09/2016

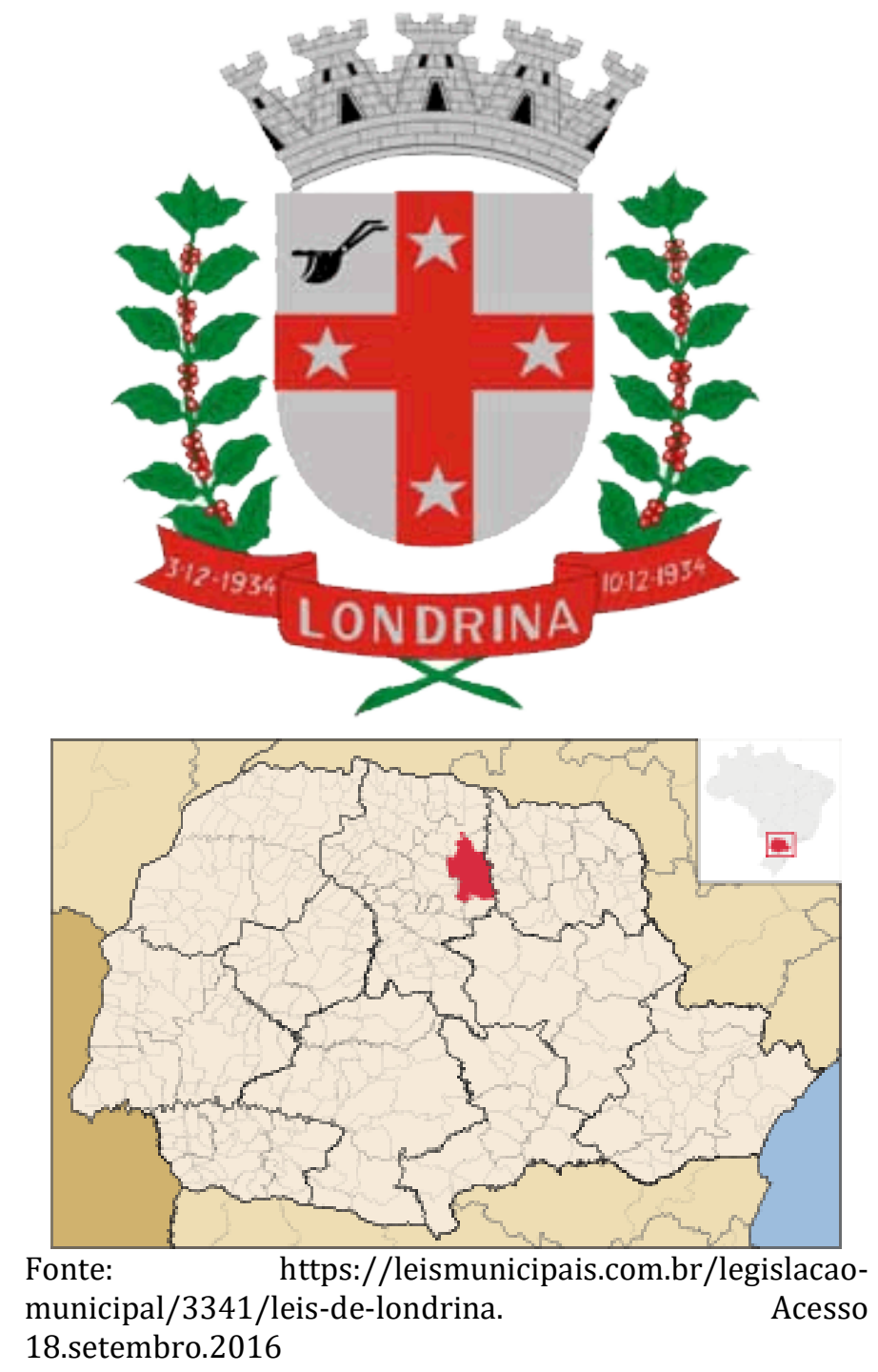

1 Graduada em Serviço Social pela Universidade Estadual de Londrina. Especialista em Gestão de Políticas Públicas pelo IFPR. Mestre em Ciências Sociais pela UFPR. Assistente Social efetiva do Governo do Estado do Paraná, com atuação na defesa dos direitos humanos de crianças e adolescents e na política de assistência social. Endereço eletrônico: carlaalves@onda.com.br 


\section{FAMÍLIAS E ELEIÇõES MUNICIPAIS EM LONDRINA - PARANÁ}

Carla Andréia Alves da Silva Marcelino

A cidade de Londrina, localizada ao Norte do Estado do Paraná, é uma cidade de grande porte, que conta com pouco mais de 80 anos de existência, sendo fruto de um processo de colonização planejada, iniciada pelos ingleses e continuada pelos agricultores do interior de São Paulo, principalmente, mas também de outros Estados, como Minas Gerais. Com cerca de 500 mil habitantes, conforme projeção do IBGE, apesar da intensa atividade urbana de comércio e um parco processo de industrialização, Londrina ainda tem a sua economia movida pelo agronegócio. Agronegócio este que por muitos anos dominou a cidade politicamente de forma direta, com representes desta área no poder, mas também indiretamente, financiando e apoiando candidatos representantes dos interesses desta fração da classe dominante. Conforme apontado em pesquisa de mestrado desta autora, a qual resultou na dissertação intitulada "Poder Político e Parentesco no Município de Londrina Paraná" ${ }^{2}$, desde o início das atividades da cidade, Londrina vem sendo dominada por pessoas advindas das "cadeiras" da diretoria de duas importantes instituições: Sociedade Rural do Paraná - SRP e Associação Comercial e Industrial de Londrina - ACIL. Estes são dois importantes locus de organização da classe dominante londrinense, sendo que ocupar um cargo nelas é um capital político valiosíssimo para aqueles que pretendem adentrar para o grupo político dominante local.

As eleições municipais em curso em Londrina são o reflexo da cultura política local. 0 prefeito atual da cidade, Alexandre Lopes Kireff, é um representante nato do agrobusiness. Expresidente da SRP, tido como o candidato da "mudança" em 2012, representando no imaginário popular o "novo" na política, um estabelecido que quis fazer-se parecer um

\footnotetext{
2 Trabalho na íntegra disponível em: http://acervodigital.ufpr.br/bitstream/handle/1884/38289/R\%20\%20D\%20-\%20CARLA\%20ANDREIA\%20ALVES\%20DA\%20SILVA.pdf
} 
outsider $^{3}$ que elegeu-se prefeito com uma virada espetacular sobre o candidato da família Belinati, sem nunca ter ocupado cargo no poder público. Contrariando as expectativas, Kireff anunciou em maio de 2016 que não tentaria a reeleição neste processo eleitoral, alegando não ser um "político profissional", conforme declaração publicada amplamente na imprensa e nas suas páginas nas redes sociais:

Não concordo com a política da forma como muitos fazem. Nem bem se elegem para um cargo já estão de olho em outro. Isso não é bom para a cidade, para o Estado e para o País. Londrina tem nomes muito bons para concorrer. 0 que aconteceu comigo pode voltar a acontecer. A cidade está amadurecendo, vendo que é possível fazer uma administração correta, sem o leilão de cargos e secretarias. É nisso que acreditamos. Na minha avaliação, esse negócio de político profissional está com os dias contados ${ }^{4}$.

Nas "alcovas" do cenário político londrinense o que se diz é que Kireff não teria aguentado a pressão política do modus operandi local, já conhecido nacionalmente pelas supostas práticas de corrupção envolvendo nomes como Janene, Belinati, Barbosa Neto, dentre outros, e teria deixado o cenário, já que é empresário bem sucedido e não precisa "viver de política" como tem dito em suas redes sociais. Apesar de não disputar, Kireff está tentando alavancar o candidato do PSDB, Valter Orsi, o qual foi presidente da ACIL entre os anos de 1998 e 2000 e entre 2014 e 2016. Orsi, assim como Kireff, nunca ocupou cargos no poder público. É proprietário de tradicional indústria local da área metalúrgica, especializada em equipamentos do ramo frigorífico. Além de presidente da ACIL, Orsi já ocupou a presidência do Sindicato das Industrias Metal Mecânica de Londrina e da Garantinorte (sociedade de garantia de crédito local). Bastante conhecido no meio empresarial, é tido como pessoa de perfil agregador e bom administrador. Apesar de não ter ocupado cargo público nomeado ou eletivo, Orsi ganhou notoriedade por ter sido um dos líderes do movimento "Pés Vermelhos, Mãos Limpas”, o qual organizou a pressão popular e os movimentos contrários à

3 Os termos outsiders e estabelecidos advêm da obra de Norbert Elias, intitulada "Os Estabelecidos e os Outsiders", na qual designa como estabelecidos os moradores tradicionais de uma comunidade, bem adaptados ao grupo e com cultura e valores bastante arraigados; os outsiders seriam os "forasteiros", os recém-chegados que tentam adentrar nessa comunidade fechada.

4 Kireff anuncia que não vai disputer a reeleição. Disponível em: http://www.fabiocampana.com.br/2016/05/kireeff-anuncia-que-nao-vai-disputar-a-reeleicao/>. Acesso em 9 set 2016. 
Antonio Belinati, entre os anos de 1998 e 2000, que culminaram na cassação do então prefeito $^{5}$.

A coligação de Orsi aglutina grande parte dos partidos da extrema direita local, dentre eles o PSD e o PSC, tendo como principais apoiadores, além de Kireff, o deputado federal, exSecretário de Fazenda do Paraná e "eterno" candidato a prefeito de Londrina, Luiz Carlos Hauly, do PSDB. 0 candidato declara em bens a quantia de $\mathrm{R} \$ 1.284 .957,35$ (hum milhão, duzentos e oitenta e quatro mil e novecentos e cinquenta e sete reais e trinta e cinco centavos), dentre eles as cotas de sua indústria, imóveis e lotes de terras. Orsi tem como vice Ricardo Hoefel Rezende, membro da diretoria executiva da SRP, agropecuarista criador de gado Nelore e de cavalos marchadores. Um autêntico "Bloco no Poder", como analisaria Nikos Poulantzas, sociólogo grego, o qual afirma que este bloco é a soma das diferentes frações da classe dominante de cada localidade.

Liderando a chapa que está à frente atualmente e reafirmando o ciclo político local que vem se repetindo desde a década de 1960, está Marcelo Belinati Martins, candidato do PP, sobrinho de Antonio Casemiro Belinati. Antonio Casemiro foi três vezes prefeito de Londrina, patriarca da família que há mais de 40 (quarenta) anos vem dominando politicamente Londrina, com forte inserção na elite política estadual do Paraná e mais de 10 (dez) membros que já ocuparam e ainda ocupam uma soma de mais de 40 (quarenta) cargos públicos eletivos ou de livre nomeação (cargos comissionados) em âmbito municipal, estadual e nacional.

Marcelo Belinati nasceu em Londrina, em 1971. É médico dos sistemas de atendimento móvel de urgência e emergência, atua também no setor privado de saúde, além de ser formado em Direito pela UEL. Marcelo já disputou quatro eleições municipais, tendo sido derrotado em duas delas, uma para vereador e outra para prefeito. Nas eleições do ano 2000, Marcelo Belinati foi lançado pelo tio, Antonio Casemiro, como candidato a vereador, pelo PSB, o qual obteve 1.631 votos, quantidade insuficiente para a obtenção da vaga ou da suplência. Possivelmente, a votação pequena (diante das grandes votações costumeiramente obtidas pelos Belinatis) tenha sido reflexo do processo ainda muito recente da cassação de seu tio, no mesmo ano 2000. Em 2004, a força do nome da família Belinati fica estampada na

\footnotetext{
${ }^{5}$ A história deste movimento pode ser melhor conhecida por meio da obra: CÉZAR, Délio Nunes. A primavera de Londrina: o despertar de uma cidade contra a corrupção. Londrina: Midiograf, 2001.
} 
votação massiva obtida por Marcelo Belinati, o qual obteve o primeiro lugar na eleição para vereador, pelo PSL, com 6.578 votos. Em 2008, Marcelo repete o feito, confirmando a tradição da família, e reelege-se vereador com mais de 8.000 votos, sendo novamente o primeiro colocado.

Nas eleições municipais de 2012, o médico, advogado e vereador Marcelo Belinati Martins, concorreu ao cargo de Prefeito de Londrina, pelo PP. Tendo como principais adversários o ruralista e representante do agrobusiness, já citado aqui, Alexandre Kireeff (PSD), a ex-Ministra do Desenvolvimento Social, Márcia Lopes (PT), o ex-prefeito de Londrina que teve o mandato cassado em 2012, Barbosa Neto (PDT) e o também ex-prefeito Luiz Eduardo Cheida (PMDB). É evidente que o sobrenome e a tradição política da família são essenciais para Marcelo Belinati, mas tem-se que reconhecer, conforme noticiado no blog "No Momento"6, que Marcelo tem grande envolvimento com a área da saúde, gozando de bastante prestígio com os trabalhadores dessa área e com a população usuária dos serviços de saúde pública do município.

Num processo eleitoral diferenciado, no qual não houve polarização entre dois partidos/candidatos, mas sim uma liderança absoluta de Marcelo Belinati nas pesquisas, sempre com 40 a $50 \%$ das intenções de votos contra parcos 10 a 15\% dos demais candidatos, e contando com apoio total do Governo do Estado do Paraná, na pessoa do Governador Beto Richa, Marcelo quase venceu o pleito no primeiro turno, obtendo 45,9\% dos votos válidos contra 25,27\% de Alexandre Kireeff, que vinha oscilando entre a segunda e a terceira colocação com Márcia Lopes, conforme os resultados divulgados pelos institutos de pesquisas ${ }^{7}$. No segundo turno, mesmo com o apoio da máquina do Governo do Estado e do seu tio, Antonio Casemiro Belinati, Marcelo perdeu para Kireeff, de forma muito disputada, sendo $48,14 \%$ contra $47,12 \%$ dos votos válidos.

\footnotetext{
6 Marcelo Belinati no PSDB?. Disponível em < http://www.nomomento.jor.br/novo/nomomento/marcelobelinati-no-psdb>. Acesso em 23 ago. 2013. 
Em reportagem da Folha de Londrina on line ${ }^{8}$, na qual se faz uma análise sobre os resultados das eleições majoritárias de 2012 em Londrina, por zona eleitoral, é possível ver que Marcelo Belinati venceu as eleições nas zonas localizadas nas periferias, mas principalmente, na Zona Norte da cidade, onde estão localizados os "Cinco Conjuntos", mostrando que até os dias atuais os conjuntos habitacionais construídos por seu tio, Antonio Belinati, e marcas da sua gestão, ainda lhe rendem soberania em relação ao voto popular. Kireeff, por sua vez, ganhou a eleição somente nas zonas eleitorais do Centro da cidade e parte da Leste e Sul. Este resultado gerou um debate nas redes sociais acerca da afirmação "A Gleba é que manda em Londrina agora", fazendo alusão ao bairro emergente (Gleba Palhano) situado entre o centro e a zona sul da cidade, em grande fase de expansão, com prédios e imóveis de luxo.

Nas eleições de 2014, Marcelo Belinati pleiteou o cargo de Deputado Federal, angariando mais um grande êxito para a família Belinati, consolidando-se ele, Marcelo, como atual sucessor do tio na continuidade do "Belinatismo" em Londrina e no Paraná. Marcelo foi o décimo segundo mais votado para a Câmara Federal, com 137.817 votos, pelo PP.

Nas eleições atuais, conforme pesquisa divulgada pela rede RPC de televisão, em 23 de agosto de $2016^{9}$, Marcelo Belinati possui cerca de 55\% das intenções de votos, tanto na pesquisa espontânea quanto na dirigida, contra os menos de 10\% de Valter Orsi, do PSDB, e de Sandra Graça, do PRB, com probabilidades reais de eleger-se no primeiro turno. Importante ressaltar que apesar do capital político acumulado pelo sobrenome Belinati, Marcelo não usa a imagem do seu tio, patriarca da família, Antonio Casemiro, e este não vem aparecendo publicamente na campanha do sobrinho, fazendo parecer que Marcelo está dissociado do tio, possuindo “vida própria” na política. 0 candidato a vice de Marcelo é João Mendonça, do PMDB, e a coligação ainda é composta pelos partidos PTB, PSL, PRP, PRTB, PMB, PROS e PR. João é microempresário, filiado ao PMDB há mais de 30 anos, sendo o atual presidente do partido em Londrina. Já foi vereador e Secretário Municipal de Meio Ambiente,

\footnotetext{
${ }^{8}$ Marcelo vence no norte; Kireeff vai bem no centro. Disponível em <http://www.folhaweb.com.br/?id folha=21--1180-20121009>. Acesso em 14 ago. 2013.

${ }^{9}$ Belinati lidera disputa para prefeitura de Londrina com 55\%. Disponível em: <http://g1.globo.com/pr/nortenoroeste/eleicoes/2016/noticia/2016/08/belinati-lidera-disputa-para-prefeitura-de-londrina-com-55-dizibope.html>. Acesso em 09 set 2016.
} 
tendo atuado também na Casa Civil no Governo do Estado do Paraná e como conselheiro da Sercomtel, companhia de telefonia pública de Londrina.

Ainda sobre Marcelo, como já dissemos, este é sobrinho de Antonio Casemiro Belinati e de Emília Salles Belinati, ex-esposa de Antonio, duas vezes vice-governadora do Paraná, exdeputada e ocupante de diversos cargos públicos de livre nomeação em importantes órgãos estaduais, tais como a Sanepar. É filho de Marlene Belinati Martins, uma das 11 irmãs/irmãos de Antonio Casemiro. Seu pai faleceu aos 28 anos de idade em um trágico acidente de automóvel, quando Marcelo ainda era criança. Marcelo tem apenas um irmão, Flademir Jerônimo Belinati Martins, o qual é juiz da Justiça Federal. Marcelo também é sobrinho de Waldmir Belinati, médico, ex-vereador, ex-deputado e ex-presidente do já extinto IPÊ (caixa de aposentadoria e serviços de saúde dos servidores estaduais do Paraná); de José Belinati Filho, também ex-vereador; de Roberval Belinati, ex-vereador e atualmente Desembargador do Tribunal de Justiça do Distrito Federal e dos Territórios; de Wanderley Belinati, funcionário aposentado da Assembleia Legislativa do Estado do Paraná e de Antonieta Belinati, atual vice-prefeita do município de Marialva-PR. É também primo de Antonio Carlos Belinati, o Tonico Belinati, ex-deputado estadual, ex-presidente da COMURB e atual Diretor Comercial da Sanepar; de Cynthia e Simone Belinati, a primeira ex-funcionária da ALEP, comissionada por mais de 15 anos e a segunda funcionária efetiva da mesma casa; de Marcos Belinati, delegado da Polícia Civil, ex-Chefe de Subdivisão Policial e atual vereador em Londrina; de Dante Belinati Guazzi, proprietário de empreiteira de obras públicas que atualmente encontra-se executando obras do Programa Minha Casa, Minha Vida; de Geysa Belinati Guazzi, casada com Gino Azzolini Neto, filho de ex-prefeito do município de Cornélio Procópio, ele próprio ex-vereador na mesma cidade, ex-diretor da COPEL, ex-Secretário de Governo do Município de Londrina e apontado como o grande operador do caso AMA/COMURB e homem de extrema confiança de Antonio Casemiro Belinati. Além destes principais parentes, conforme apontamos na dissertação já citada nesta notícia, a família Belinati acumula ainda uma série de outros membros ocupantes de cargos comissionados nas esferas municipal, estadual e nacional.

Apesar de Orsi e Belinati virem polarizando o processo eleitoral, com larga vantagem para Belinati, existem ainda outros cinco candidatos. Haviam seis, mas a candidata da REDE, 
Flávia Romagnoli, teve sua candidatura impugnada a pedido do próprio partido. Os demais candidatos são Sandra Graça, vereadora por quatro mandatos, funcionária pública da Caixa Econômica Federal, tendo ocupado por várias vezes cargos em associações de servidores e gerentes daquela instituição. Viúva, acumula com a vereança funções de administração do seu agronegócio com plantio de soja e laranja. Conforme informa o blog de política londrinense "Paçoca com Cebola"10, Sandra sempre foi pessoa forte do grupo de Antonio Belinati, tendo integrado os quadros do PP de Londrina até 2013, saindo do partido após sentir-se "escanteada" pelo grupo. O vice de Sandra Graça é o servidor público municipal de Londrina, Marcos Urbaneja, do PDT; Marcos é irmão de Marcelo Urbaneja, sindicalista muito conhecido em Londrina, vinculado há anos ao sindicado dos servidores daquele município.

Outro candidato é Luciano Odebrecht, do PMN. Apesar do nacionalmente conhecido sobrenome, não conseguimos localizar qualquer relação direta de parentesco do candidato com a Construtora Odebrecht. 0 candidato é advogado, mestre em direito constitucional, professor da Universidade Estadual de Londrina e esta é a sua primeira incursão na política. 0 vice de Luciano é o jovem advogado Gabriel Antunes da Silva, também do PMN.

O candidato do PPS é André Trindade, também advogado e professor universitário da rede privada de ensino de Londrina; o candidato a vice na sua chapa é Cristian França, advogado, filiado ao PSB. Temos ainda o candidato do PT, Odarlone Santos de Souza Orente, conhecido líder estudantil londrinense, estudou medicina em Cuba, médico de família e já ocupou cargos públicos, como o de Superintendente do Estratégia Saúde da Família - ESF, no município de Apucarana. A vice de Ordarlone é Celiana Lucia da Silva, professora da rede pública, filiada ao PPL. Por fim, temos o candidato do PSOL, o estudante universitário de psicologia, Paulo Silva, o qual fez parte da gestão do Diretório Central dos Estudantes - DCE da UEL; Paulo tem como vice o economista Walter Diesel.

Fazendo uma breve análise das relações de parentesco dos candidatos a vereador, constatamos representantes das tradicionais famílias "da política" local e estadual, com alguns novos membros estreando na vida política, tal como Guilherme Antonio Belinati Pereira, do

10 Sandra pode ser a novidade na campanha para prefeito de Londrina. Disponível em: < http://www.pacocacomcebola.com.br/geral/sandra-graca-pode-ser-a-novidade-na-campanha-para-prefeito-delondrina/>. Acesso em 12 set 2016. 
PP, neto de Antonio Casemiro Belinati e Emília Salles Belinati, filho Simone Belinati. Gui Belinati, como é conhecido, tem 27 anos e é estudante universitário do curso de Direito da rede particular. Recentemente, em uma rede social, Antonio Casemiro Belinati declarou que Gui é o "escolhido" para ser o seu sucessor na política.

Outro nome já conhecido, visto que é candidato à reeleição, é Gustavo Corulli Richa, do PSDB, advogado, filho de Jamil Richa (irmão do ex-governador José Richa) e Maria Elenice Rocha Corulli, portanto primo do atual Governador do Estado do Paraná, Beto Richa. Gustavo elegeu-se vereador em Londrina nas eleições de 2012, pelo PHS, com 3.737 votos. Com uma campanha em que foram declarados gastos de apenas $\mathrm{R} \$ 4.860,00$, advindos de recursos próprios e doação de uma pessoa física, conseguiu ser o sexto vereador mais votado (em números absolutos), votação bastante expressiva para o jovem de sobrenome famoso, mas completamente desconhecido na política local. Gustavo Richa candidatou-se ao cargo de deputado estadual em 2014, sem sequer ter cumprido sua primeira legislatura em Londrina e obteve os poucos 10.182 votos, ficando na suplência. Curioso observar como além do capital político, em apenas tão pouco tempo, Gustavo também "adquiriu" prestígio (ou herdou-o) junto aos detentores do capital econômico. Prova disso é que diferentemente da modesta campanha de 2012 para vereador, em 2014 Gustavo contou com quase R 2.000.000,00 em gastos. Dentre os seus principais doadores estão seu primo, Carlos Alberto Richa, a COTRANS Locação de Veículos Ltda. e Loteadora Tupy, conforme divulgado no portal DivulgaCand2014 do Tribunal Superior Eleitoral. Como é de conhecimento público, a COTRANS é uma empresa do ramo de locação de veículos a qual mantém contrato com a Prefeitura Municipal de Curitiba desde os tempos em que Beto Richa era prefeito da capital paranaense.

Outro conhecido nome é o candidato à reeleição, Jamil Janene, do PP, sobrinho do exdeputado e grande articulador político de projeção nacional, José Janene. Jamil ocupou o cargo de vereador entre os anos de 2001 e 2008, pelo PDT, obtendo sempre votações expressivas. Em 2006 tentou o cargo de deputado estadual, sem sucesso. Em 2012, agora no partido no qual seu tio, José Janene, construiu sua carreira política, o PP, Jamil retornou à vereança, com mais de três mil votos. Jamil destacou-se neste último mandato como vereador por ser o único membro do legislativo municipal a declarar-se de oposição ao atual prefeito Alexandre Kireff. 
Nesta breve análise acerca das eleições municipais de 2016 em Londrina não temos nenhuma novidade, mas sim uma simples repetição do cenário político local desde o surgimento da cidade, tendo a polarização da classe economicamente dominante vinculada à indústria/comércio e ao agronegócio, e os hoje estabelecidos membros da família Belinati. Apesar de parecerem estar em lados opostos, a história da cidade mostra que a classe politicamente dominante está sempre em convergência com a classe politicamente dominante. Portanto, vencendo Marcelo Belinati ou Valter Orsi, temos a convicção de que talvez a forma de administração do município se altere, já que atualmente a prefeitura tem um caráter mais tecnicista, empresarial, estilo bem diferente da família Belinati, mas certamente os interesses em jogo serão os mesmos. Outrossim, hoje temos Marcelo Belinati na "berlinda", mas o patriarca dos Belinatis já deixa claro que prepara seu sucessor, garantindo assim a reprodução da família na política local por muitos anos ainda. 